\title{
Dos meios às mediações: 3 introduções ${ }^{1}$
}

From the media to mediations: 3 introductions

- JESÚS MARTÍN-BARBERO

\section{DOS MEIOS ÀS MEDIAÇÕES ${ }^{2}$}

N ESTE LIVRO, MARTÍN-BARBERO aborda o conflito entre emissores e receptores, e o fato de que nem sempre estes últimos são seduzidos sem resistência; a produção de sentido para além da mídia massiva; e os processos sociais que na América Latina rompem as velhas certezas, nos confrontando com a verdadeira cultura desses países. A comunicação se torna uma questão de cultura, que exige rever todo o processo de mediação de massa a partir da recepção, do reconhecimento e da apropriação. Este deslocamento metodológico implica uma nova visão da modernidade latino-americana e de suas perspectivas, não por meio da dissidência cultural autodesenvolvida ou do legado tradicional, mas mediante o estudo da potência, densidade e pluralidade das culturas populares e de sua relação com o surgimento histórico das massas. "A aposta e o objetivo deste livro" - diz ele - “é tornar investigáveis os processos de constituição da massa para além da chantagem culturalista que inevitavelmente os transforma em processos de degradação cultural", evitando que "a presença do povo na massa" nos faça esquecer a necessária crítica de que tudo o que no massivo mascara a desigualdade social e é um dispositivo de integração ideológica.

O que será exposto traz as marcas de uma longa jornada. Vinha eu da filosofia e, pelos caminhos da linguagem, me deparei com a aventura da comunicação. De um espaço heideggeriano, vim parar entre homens e barracos construídos em pau a pique, mas com transmissores de rádios e antenas de TV. Desde então trabalho aqui, no campo da mediação de massa, de seus dispositivos de produção e seus rituais de consumo, seus aparatos tecnológicos e suas exposições, seus códigos de montagem, de percepção e reconhecimento.

DOI: http://dx.doi.org/10.11606/issn.19\$2-\$160.v1 2i1 p9-31 V.12 - № 1 jan./abr. 201 S São Paulo - Brasil JESÚS MARTÍN-BARBERO p. 9-31
Tradução: Fernanda Castilho (primeira e terceira introdução) e Maria Immacolata Vassallo de Lopes (segunda introdução).

${ }^{1}$ Cada um dos textos seguintes constitui uma das introduções, escritas pelo autor, a determinada edição do livro De los medios a las mediaciones: comunicación, cultura y hegemonía.

${ }^{2}$ Introdução à edição de 1987, da editora Gustavo Gili, Barcelona. 
Por um tempo, o trabalho consistiu em investigar como nos manipula esse discurso que por meio da mídia massiva torna suportáveis as inverdades, como a ideologia penetra as mensagens impondo à comunicação a lógica da dominação. Por meio da sociolinguística e da semiótica, levei a cabo leituras ideológicas de textos e práticas, e deixei mostra e registro de tudo em um livro que intitulei, sem esconder influências, Comunicação massiva: discurso e poder (Martín-Barbero, 1978). Mesmo assim, já na época - estou falando de dez anos atrás - alguns pesquisadores começavam a suspeitar daquela imagem do processo de estratégias do dominador, na qual não cabiam mais figuras além das estratégias do dominador, em que tudo se resumia a emissores dominantes e receptores dominados, sem o menor sinal de sedução ou resistência, em que na estrutura da mensagem não existiriam os conflitos nem as contradições, nem sequer as lutas. Por volta desses anos, algo estremeceu nossa realidade - por essas latitudes, os terremotos não são incomuns - tão fortemente que trouxe à tona e tornou visível o profundo desencontro entre método e situação: todos os modos como as pessoas produzem sentido em suas vidas, os modos como se comunicam e usam os meios, não se encaixavam naquele modelo. Dito em outras palavras: os processos políticos e sociais desta época - regimes autoritários em quase toda a América do Sul, cercados de lutas de libertação na América Central, grandes migrações de homens da política, da arte e da investigação social -, destruíram velhas certezas e abriram novas brechas, nos confrontaram com a verdade cultural desses países: a mestiçagem, que não é apenas aquele fato racial do qual viemos, mas a atual trama da modernidade e das descontinuidades culturais, de formações sociais e estruturas de sentimento, de memórias e imaginários que misturam o indígena com o rural, o rural com o urbano, o folclore com o popular e o popular com o massivo.

Foi assim que a comunicação se tornou uma questão de mediações mais do que de meios, uma questão de cultura e, portanto, não só de conhecimento, mas de reconhecimento. Um reconhecimento que foi, a princípio, uma operação de deslocamento metodológico para re-ver todo o processo da comunicação a partir de seu outro lado, o da recepção, o lugar das resistências e da apropriação a partir de seus usos. Mas num segundo momento, tal reconhecimento, justamente para que esse deslocamento não virasse mera reação ou mudança teórica passageira, se transformou em re-conhecimento da história: reapropriação histórica do tempo da modernidade latino-americana e de seu descompasso, que abre uma brecha na lógica enganosa pela qual a homogeneização capitalista parece esgotar a realidade presente. Pois na América Latina a diversidade cultural não significa, como talvez na Europa e nos Estados Unidos, a dissidência contracultural ou o museu, mas a vigência, a densidade e a pluralidade das culturas populares, 
o espaço de um conflito profundo e uma dinâmica cultural inevitável. E estamos descobrindo nos últimos anos que o popular não fala unicamente a partir das culturas indígenas ou rurais, mas também a partir da trama espessa das mestiçagens e das deformações do urbano, do massivo. Da mesma forma, ao menos na América Latina, contrariamente às profecias de destruição do social, as massas ainda contêm - no duplo sentido de controle e inclusão - o povo. Não podemos, então, pensar hoje no popular atuando à margem do processo histórico de constituição do massivo: o acesso das massas à sua visibilidade $\mathrm{e}$ presença social e da massificação que historicamente esse processo materializa. Não podemos continuar construindo uma crítica que separe a massificação da cultura do fato político que origina a emergência histórica das massas e do movimento contraditório que produz a não exterioridade do massivo ao popular, tornando-se um dos seus modos de existência. Atenção, porque o perigo se encontra tanto em confundir o rosto com a máscara - a memória popular com o imaginário de massa - como na crença que possa existir uma memória sem o imaginário, no qual se ancora o presente e se projeta o futuro. Precisamos de muita clareza para não confundi-los, de modo a pensar nas relações que hoje compõem a mestiçagem.

Essa é a aposta e o objetivo deste livro: mudar o lugar das questões, tornar investigáveis os processos de constituição do massivo para além da chantagem culturalista que inevitavelmente os transforma em processos de degradação cultural. E, para isso, investigá-los a partir das mediações e dos sujeitos, isto é, da articulação entre práticas de comunicação e movimentos sociais. Daí as suas três partes - a situação, os processos, o debate - e a sua colocação invertida: por ser o lugar de partida, a situação latino-americana terminará na exposição, convertendo-se em lugar de chegada. Espero que as marcas deixadas ao longo do caminho ativem a cumplicidade do leitor e permitam, durante essa jornada, reconhecê-la.

Falei inicialmente sobre os traços deixados pela longa jornada realizada até aqui e preciso assinalar alguns deles. Assim, na primeira parte, vemos as dificuldades de articular um discurso que, sendo uma reflexão filosófica e histórica, não se distancie muito nem pareça externo à problemática e à experiência que procura iluminar. E, às vezes, a sensação duplamente insatisfatória de ter ficado a meio caminho entre aquela e esta. Além do inegável sabor de ajuste de contas que certas páginas encerram. Há uma aparente semelhança da segunda parte com $o$ desenho de uma arqueologia baseada no passado, em seus fundamentos, a forma autêntica de alguns modos e práticas de comunicação que desapareceram ou se degradaram. Quando, na verdade, o que procuramos é algo radicalmente diferente: não o que sobrevive do passado, mas o que hoje faz com que certas matrizes 
culturais permaneçam válidas e uma narrativa anacrônica se conecte com a vida das pessoas. Finalmente, na terceira parte, a ilusória impressão de que, ao investigar as formas de presença do povo na massa, estávamos abandonando a crítica do que no massivo é disfarce e neutralização da desigualdade social e, portanto, dispositivo de integração ideológica. Talvez esse seja o preço que devemos pagar por ousar romper com uma razão dualista e afirmar o entrelaçamento de distintas lógicas no massivo, a presença nele não só das exigências do mercado, mas de uma matriz cultural e de um sensorium que repugna as elites, ao mesmo tempo em que constitui um "lugar" de interpelação e reconhecimento das classes populares.

Muitas pessoas e instituições apoiaram a pesquisa na qual este livro se baseia. Entre elas, devo agradecer especialmente à Universidad del Valle, em Cali, que concedeu uma bolsa de estudos para elaborar o projeto e reunir a documentação necessária, além de conceder tempo durante vários anos para realizar a pesquisa. Aos professores e pesquisadores de comunicação da Universidade de Lima e Autónoma Metropolitana de Xochimilco, no México, que reconheceram o valor da proposta, mesmo ainda em esboço, e me convidaram várias vezes para discutir e acompanhar seu desenvolvimento. Ao IPAL, que possibilitou visitas a vários centros de pesquisa para discussão e atualização de informações. Meus sinceros agradecimentos àquelas pessoas que não só me ajudaram no debate intelectual, mas também me apoiaram com seu carinho: Patricia Anzola, Luis Ramiro Beltrán, Héctor Schmucler, Ana María Fadul, Rosa María Alfaro, Néstor García Canclini, Luis Peirano. E Elvira Maldonado, que aguentou e acompanhou o dia a dia do trabalho.

${ }^{3}$ Prefácio à edição de 1998, Convênio Andrés Bello, Bogotá, e com versão publicada (traduzida aqui) na segunda edição brasileira do livro, de 2003, da editora da UFRJ, Rio de Janeiro.

\section{PISTAS PARA ENTRE-VER MEIOS E MEDIAÇÕES ${ }^{3}$}

Surgido em 1987, este livro chega, quatorze anos depois, à sua quinta edição latino-americana e à sua segunda edição brasileira. Sinto que isso me obriga, mais do que a atualizar seu conteúdo - é o que tratei de fazer especialmente nos trabalhos publicados desde meados dos anos 1990 -, a pensar o sentido de sua atualidade. Não são poucas as vozes que, nos últimos anos, convidaram-me a escrever um livro que responda à inversão do título, isto é, Das mediações aos meios, pois esse pareceria ser o novo rumo que está necessitando a investigação sobre as relações entre comunicação e cultura na América Latina. Porém, por trás dessa proposta se misturam visões do devir social e de projetos muito diferentes. Chego a vislumbrar pelo menos dois. Um que, partindo da envergadura econômico-cultural que adquiriram as tecnologias audiovisuais e informáticas nos acelerados processos de globalização, busca levar em conta os meios na hora de construir políticas culturais que façam frente aos efeitos dessocializadores do neoliberalismo e insiram explicitamente as indústrias culturais na construção econômica e política 
da região. O outro projeto resulta da combinação do otimismo tecnológico com o mais radical pessimismo político, e o que busca é legitimar, pelo poder dos meios, a onipresença mediadora do mercado. Pervertendo o sentido das demandas políticas e culturais, que encontram de algum modo expressão nos meios, deslegitima qualquer questionamento da ordem social à qual somente o mercado e as tecnologias permitiriam dar forma. Este último é o projeto hegemônico, que nos faz submergir numa crescente onda de fatalismo tecnológico, e frente ao qual resulta, mais necessário que nunca, manter a estratégica tensão, epistemológica e política, entre as mediações históricas que dotam os meios de sentido e alcance social e o papel de mediadores que eles possam estar jogando hoje. Sem esse mínimo de distância - ou negatividade, diriam os frankfurtianos - nos é impossível o pensamento crítico. Como assumir, então, o espessor social e perceptivo que hoje revestem as tecnologias comunicacionais, seus modos transversais de presença na cotidianidade, desde o trabalho ao jogo, suas espessas formas de mediação tanto do conhecimento como da política, sem ceder ao realismo da inevitabilidade que produz a fascinação tecnológica, e sem se deixar apanhar na cumplicidade discursiva da modernização neoliberal - racionalizadora do mercado como único princípio organizador da sociedade em seu conjunto - com o saber tecno-lógico, segundo o qual, esgotado o motor da luta de classes, a história teria encontrado seu substituto nos avatares da informação e comunicação?

A centralidade incontestável que hoje ocupam os meios resulta desproporcionada e paradoxal em países como os nossos, com necessidades básicas insatisfeitas no âmbito da educação ou da saúde, e nos quais o crescimento da desigualdade atomiza nossas sociedades, deteriorando os dispositivos de comunicação, isto é, de coesão política e cultural. E, pelo que, "desgastadas as representações simbólicas, não conseguimos fazer-nos uma imagem do país que queremos, a política não logra fixar o rumo das mudanças em marcha" (Lechner, 1995: 124). Daí que nossas populações possam, com certa facilidade, assimilar as imagens da modernização e não poucas mudanças tecnológicas, porém, somente muito lenta e dolorosamente, possam recompor seus sistemas de valores, normas éticas e virtudes cívicas. Tudo isso nos exige continuar o esforço por desentranhar a cada dia mais complexa trama de mediações que articula a relação comunicação/cultura/política.

Do lado da comunicação, o que hoje necessitamos pensar é um processo no qual o que está em jogo já não é a dessublimação da arte, simulando, na figura da indústria cultural, sua reconciliação com a vida, como pensavam os frankfurtianos, senão a emergência de uma razão comunicacional, cujos dispositivos - a fragmentação que desloca e descentra, o fluxo que globaliza e comprime, a conexão que desmaterializa e hibridiza - agenciam o devir mercado 
da sociedade. Frente ao consenso dialogal em que Habermas vê emergir a razão comunicativa, descarregada da opacidade discursiva e a ambiguidade política que introduzem a mediação tecnológica e mercantil, o que tentamos pensar é a hegemonia comunicacional do mercado na sociedade: a comunicação convertida no mais eficaz motor de desengate e de inserção das culturas - étnicas, nacionais ou locais - no espaço/tempo do mercado e nas tecnologias globais. No mesmo sentido, estamos necessitando pensar o lugar estratégico que passou a ocupar a comunicação na configuração dos novos modelos de sociedade, e sua paradoxal vinculação tanto com o relançamento da modernização - via satélites, informática, videoprocessadores - como com a desconcertada e tateante experiência da tardomodernidade.

Do lado da cultura, até há relativamente poucos anos, o mapa parecia claro e sem rugas: a antropologia tinha a seu encargo as culturas primitivas e a sociologia se encarregava das modernas. O que implicava duas ideias opostas de cultura: para os antropólogos, cultura é tudo, pois no magma primordial que habitam os primitivos, cultura é tanto o machado como o mito, a oca como as relações de parentesco, o repertório das plantas medicinais ou das danças rituais; enquanto para os sociólogos, cultura é somente um tipo especializado de atividades e de objetos, de práticas e produtos pertencentes ao cânone das artes e das letras. Na tardomodernidade que agora habitamos a separação que instaurava aquela dupla ideia de cultura se vê borrada, de uma parte, pelo movimento crescente de especialização comunicativa do cultural, agora organizado em um sistema de máquinas produtoras de bens simbólicos ajustados a seus "públicos consumidores". É o que hoje faz a escola com seus alunos, a televisão com suas audiências, a igreja com seus fiéis ou a imprensa com seus leitores. E, de outra parte, é toda a vida social que, antropologizada, se torna cultura. Como se a máquina da racionalização modernizadora, impossível de ser detida - que separa e especializa - estivesse girando, patinando, em círculos, a cultura escapa a toda compartimentalização, irrigando a vida social por inteiro. Hoje são sujeito/objeto de cultura tanto a arte como a saúde, o trabalho ou a violência, e há também cultura política, do narcotráfico, cultura organizacional, urbana, juvenil, de gênero, cultura científica, audiovisual, tecnológica etc.

No que concerne à política, o que estamos vivendo não é, como creem os mais pessimistas dos profetas-fim-de-milênio, a sua dissolução, senão a reconfiguração das mediaçães em que se constituem os novos modos de interpelação dos sujeitos e de representação dos vínculos que coesionam a sociedade. Mais que a substituir, a mediação televisiva ou radiofônica passou a constituir, a fazer parte da trama dos discursos e da própria ação política. Pois essa mediação é socialmente produtiva, e o que ela produz é a densificação das dimensões rituais e teatrais 
da política. Produção que permanece impensada, e em boa medida impensável, para a concepção instrumental de comunicação que permeia boa parte da crítica. Pois, o meio não se limita a veicular ou a traduzir as representações existentes, nem tampouco pode substituí-las, senão que começou a constituir uma cena fundamental da vida pública. E o faz reintroduzindo, no âmbito da racionalidade formal, as mediações da sensibilidade que o racionalismo do "contrato social" acreditou poder (hegelianamente) superar. Se a televisão exige da política negociar as formas de sua mediação, é porque, como nenhum outro, esse meio lhe dá acesso ao eixo do olhar (Verón, 1987), a partir do qual a política pode não só penetrar o espaço doméstico, como também reintroduzir em seu discurso a corporeidade, a gestualidade, isto é, a materialidade significante de que está constituída a interação social cotidiana. Se falar de cultura política significa levar em conta as formas de intervenção das linguagens e culturas na constituição dos atores e do sistema político (Landi, 1988), pensar a política a partir da comunicação significa pôr em primeiro plano os ingredientes simbólicos e imaginários presentes nos processos de formação do poder - o que leva a democratização da sociedade em direção a um trabalho na própria trama cultural e comunicativa da política. Pois nem a produtividade social da política é separável das batalhas que vêm à luz no terreno simbólico, nem o caráter participativo da democracia é hoje real fora da cena pública que constrói a comunicação massiva.

Então, mais do que objetos de políticas, a comunicação e a cultura constituem hoje um campo primordial de batalha política: o estratégico cenário que exige que a política recupere sua dimensão simbólica - sua capacidade de representar o vínculo entre os cidadãos, o sentimento de pertencimento a uma comunidade - para enfrentar a erosão da ordem coletiva. Que é o que o mercado não pode fazer (Brunner, 1990), por mais eficaz que seja seu simulacro. O mercado não pode sedimentar tradições, já que tudo o que produz "desmancha no ar", dada sua tendência estrutural a uma obsolescência acelerada e generalizada não somente das coisas, mas também das formas e instituições. O mercado não pode criar vínculos societais, isto é, entre sujeitos, pois estes se constituem nos processos de comunicação de sentido, e o mercado opera anonimamente mediante lógicas de valor que implicam trocas puramente formais, associações e promessas evanescentes que somente engendram satisfações ou frustrações, porém nunca sentido. O mercado não pode engendrar inovação social, pois esta pressupõe diferenças e solidariedades não funcionais, resistências e dissidências, enquanto o mercado trabalha unicamente com rentabilidade.

Buscando traçar um novo mapa das mediações, das novas complexidades nas relações constitutivas entre comunicação, cultura e política, venho nos últimos anos trabalhando a seguinte proposta: 


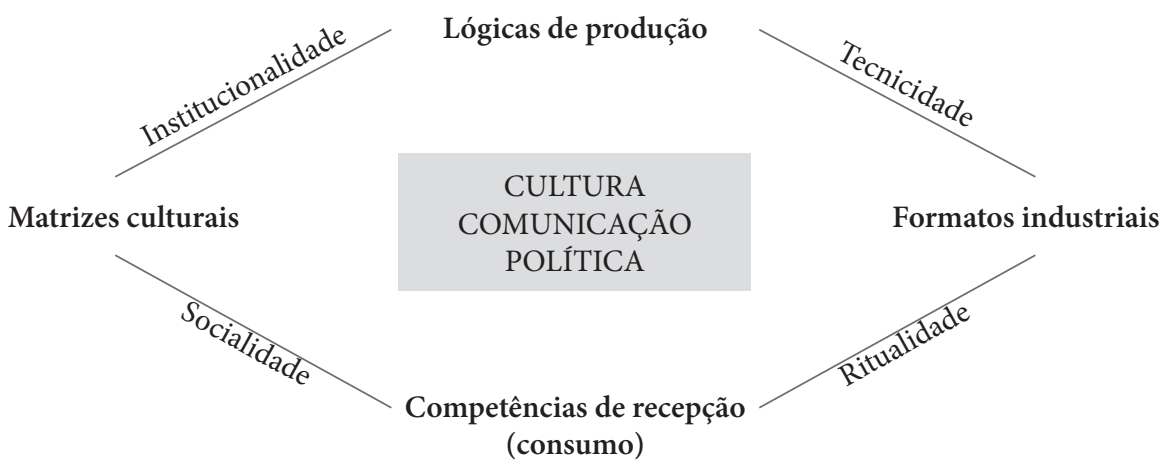

O esquema se move sobre dois eixos: o diacrônico, ou histórico de longa duração - entre Matrizes Culturais (MC) e Formatos Industriais (FI) - e o sincrônico: entre Lógicas de Produção (LP) e Competências de Recepção ou Consumo (CR). Por sua vez, as relações entre MC e LP encontram-se mediadas por diferentes regimes de institucionalidade, enquanto as relações entre MC e CR estão mediadas por diversas formas de socialidade. Entre as LP e os FI mediam as tecnicidades e entre os FI e as $\mathrm{CR}$ mediam as ritualidades.

1. A relação entre Matrizes Culturais e Formatos Industriais remete à história das mudanças na articulação entre movimentos sociais e discursos públicos, e destes com os modos de produção do público que agenciam as formas hegemônicas de comunicação coletiva. Um exemplo: ligado inicialmente aos movimentos sociais dos setores populares nos começos da revolução industriale ao surgimento da cultura popular de massas, que ao mesmo tempo nega e afirma o popular, transformando seu estatuto cultural, o gênero melodrama será primeiro teatro e tomará depois o formato de folhetim ou novela em capítulos - no qual a memória popular (as relações de parentesco como eixo da trama) irá se entrecruzar, hibridizar, com o imaginário burguês (das relações sentimentais do casal) - e daí passará ao cinema, especialmente norte-americano, e na América Latina ao radioteatro e à telenovela. Essa história nos permite deslocar o maniqueísmo estrutural que nos incapacitou durante muito tempo de pensar a espessura das cumplicidades entre discursos hegemônicos e subalternos, assim como a constituição - ao longo dos processos históricos - de gramáticas discursivas originadas de formatos de sedimentação de saberes narrativos, hábitos e técnicas expressivas. Gramáticas generativas, que dão lugar a uma topografia de discursos movediça, cuja mobilidade provém tanto das mudanças do capital e das transformações 
tecno-lógicas como do movimento permanente das intertextualidades e intermedialidades que alimentam os diferentes gêneros e os diferentes meios. E que hoje são lugar de um complexo entremeado de resíduos (R. Williams) e inovações, de anacronias e modernidades, de assimetrias comunicativas que envolve, da parte dos produtores, sofisticadas "estratégias de antecipação" (M. Wolf) e, da parte dos espectadores, a ativação de novas e velhas competências de leitura. Essa história passa hoje justamente pela perspectiva dos chamados "estudos culturais".

2. A dupla relação das $\mathrm{MC}$ com as Competências de Recepção e as Lógicas de Produção é mediada pelos movimentos de socialidade, ou sociabilidade, e pelas mudanças na institucionalidade. A socialidade, gerada na trama das relações cotidianas que tecem os homens ao juntar-se, é por sua vez lugar de ancoragem da práxis comunicativa e resulta dos modos e usos coletivos de comunicação, isto é, de interpelação/constituição dos atores sociais e de suas relações (hegemonia/contra-hegemonia) com o poder. Nesse processo, as MC ativam e moldam os habitus que conformam as diversas Competências de Recepção. A institucionalidade tem sido, desde sempre, uma mediação densa de interesses e poderes contrapostos, que tem afetado, e continua afetando, especialmente a regulação dos discursos que, da parte do Estado, buscam dar estabilidade à ordem constituída, e da parte dos cidadãos - maiorias e minorias - buscam defender seus direitos e se fazer reconhecer, isto é, re-constituir permanentemente o social. Vista a partir da socialida$d e$, a comunicação se revela uma questão de fins - da constituição do sentido e da construção e desconstrução da sociedade. Vista a partir da institucionalidade, a comunicação se converte em questão de meios, isto é, de produção de discursos públicos cuja hegemonia se encontra hoje paradoxalmente do lado dos interesses privados.

As transformações na socialidade remetem a movimentos, não necessariamente fundamentalistas ou nacionalistas, que se reencontram com o comunitário, como aquele que está ocorrendo entre os jovens em torno da música, e que se acham mais bem ligados a mudanças profundas na sensibilidade e na subjetividade. A reconfiguração da institucionalidade não poderia ser mais forte, em que pese os paradoxos que apresenta: enquanto os partidos tradicionais (e não pouco dos novos também) se entrincheiram em seus feudos, as instituições estatais se corrompem até o impensável e as instituições parlamentares se burocratizam até a perversão, assistimos a uma multiplicação de movimentos em busca de outras institucionalidades, capazes de dar forma às pulsões e aos 
deslocamentos da cidadania para o âmbito cultural e do plano da representação para o do reconhecimento instituinte.

3. A compreensão do funcionamento das Lógicas de Produção mobiliza uma tríplice indagação: 1) sobre a estrutura empresarial - em suas dimensões econômicas, ideologias profissionais e rotinas produtivas; 2) sobre sua competência comunicativa - capacidade de interpelar/ construir públicos, audiências, consumidores; e 3) muito especialmente sobre sua competitividade tecnológica - usos da tecnicidade, por onde passa hoje em grande medida a capacidade de inovar nos FI. Porque a tecnicidade é menos assunto de aparatos que de operadores perceptivos e destrezas discursivas. Confundir a comunicação com as técnicas e os meios resulta tão deformador como pensar que eles sejam exteriores e acessórios à (verdade da) comunicação. Do mesmo modo, confundir o processo industrial com a rentabilidade do capital - outra coisa é visibilizar suas cumplicidades - foi o que levou a converter a crítica em evasão, pois se a racionalidade total da produção se esgota na racionalidade do sistema, não há outra forma de escapar à reprodução a não ser sendo improdutivos! A estratégica mediação da tecnicidade se coloca atualmente em um novo cenário, o da globalização, e em sua conversão em conector universal do global (Milton Santos). Isso se dá não só no espaço das redes informáticas, como também na conexão dos meios - televisão e telefone - com o computador, restabelecendo aceleradamente a relação dos discursos públicos e os relatos (gêneros) midiáticos com os formatos industriais e os textos virtuais. As perguntas abertas pela tecnicidade apontam então para o novo estatuto social da técnica, ao restabelecimento do sentido do discurso e da práxis política, ao novo estatuto da cultura, e aos avatares da estética.

4. A mediação das ritualidades nos remete ao nexo simbólico que sustenta toda comunicação: à sua ancoragem na memória, aos seus ritmos e formas, seus cenários de interação e repetição. Em sua relação com os FI (discursos, gêneros, programas e grades ou palimpsestos), as ritualidades constituem gramáticas da ação - do olhar, do escutar, do ler - que regulam a interação entre os espaços e tempos da vida cotidiana e os espaços e tempos que con-formam os meios. O que implica, da parte dos meios, certa capacidade de ditar regras ao jogo entre significação e situação. Porém, uma coisa é a significação da mensagem e outra é aquilo ao que alude a pragmática quando faz a pergunta pelo sentido que tem para o receptor a ação de ouvir rádio ou de ver televisão. Vistas desde as CR, as ritualidades remetem, de um lado, para os diferentes usos sociais dos 
meios, por exemplo, o barroquismo expressivo dos modos populares de assistir ao filme frente à sobriedade e seriedade do intelectual para quem qualquer ruído é capaz de distraí-lo de sua contemplação cinematográfica. Ou o consumo produtivo que alguns jovens fazem do computador diante do uso marcadamente lúdico-evasivo da maioria. De outro lado, as ritualidades remetem às múltiplas trajetórias de leitura ligadas às condições sociais do gosto, marcados por níveis e qualidade de educação, por posses e saberes constituídos na memória étnica, de classe ou de gênero, e por hábitos familiares de convivência com a cultura letrada, oral ou audiovisual, que carregam a experiência do ver sobre a do ler ou vice-versa.

Também as ritualidades são arrancadas do tempo arcaico, por alguns antropólogos e sociólogos, para iluminar as especificidades da contemporaneidade urbana: modos de existência do simbólico, trajetórias de iniciação e ritos "de passagem", serialidade ficcional e repetição ritual, permitindo assim entrever o jogo entre cotidianidade e experiências da diferença, da ressacralização, do reencantamento do mundo a partir de certos usos ou modos de relação com os meios, entre inércias e atividade, entre hábitos e iniciativas do olhar e do ler.

O que busco com esse mapa é reconhecer que os meios constituem hoje espaços-chave de condensação e intersecção de múltiplas redes de poder e de produção cultural, mas também alertar, ao mesmo tempo, contra o pensamento único que legitima a ideia de que a tecnologia é hoje o "grande mediador" entre as pessoas e o mundo, quando o que a tecnologia media hoje, de modo mais intenso e acelerado, é a transformação da sociedade em mercado, e deste em principal agenciador da mundialização (em seus muitos e contrapostos sentidos). A luta contra o pensamento único acha assim um lugar estratégico não somente no politeísmo nômade e descentralizador que mobiliza a reflexão e a investigação sobre as mediações históricas do comunicar, mas também nas transformações que atravessam os mediadores socioculturais, tanto em suas figuras institucionais e tradicionais - a escola, a família, a igreja, o bairro - como no surgimento de novos atores e movimentos sociais que, como as organizações ecológicas ou de direitos humanos, os movimentos étnicos ou de gênero, introduzem novos sentidos do social e novos usos sociais dos meios. Sentidos e usos que, em seus tateares e tensões remetem, de uma parte, à dificuldade de superar a concepção e as práticas puramente instrumentais para assumir o desafio político, técnico e expressivo, que ajuda o reconhecimento na prática da espessura cultural que hoje possuem os processos e os meios de comunicação. Porém, de outra parte, remetem também à lenta iluminação de novas esferas do público e às novas formas de imaginação e de criatividade social.

Essas lutas se entrecruzam com as principais lições aprendidas nestes catorze anos e traçam os caminhos da minha esperança. Pois como escreveu Borges: 
"O que chega nunca se anima a ser de todo presente sem antes ensaiar e esse ensaio é a esperança”. Refiro-me especialmente à lenta e profunda revolução das mulheres - quem sabe a única que deixa marcas deste decepcionante século na história - sobre o mundo da cultura e da política, articulando o reconhecimento da diferença com o discurso que denuncia a desigualdade, e afirmando a subjetividade implicada em toda ação coletiva. Refiro-me também às rupturas que, mobilizadas pelos jovens, ultrapassam o âmbito da geração: tudo o que a juventude condensa, em suas inquietações e fúrias como em suas empatias cognitivas e expressivas com a língua das tecnologias, de transformações no sensorium de "nossa" época e de mutações político-culturais que anunciam o novo século. E refiro-me, finalmente, a essas "novas maneiras de estar juntos" pelas quais se recria a cidadania e se reconstitui a sociedade, a partir das coletividades de bairro para a resolução pacífica de conflitos e das emissoras de rádio e televisão comunitárias em que se recuperam memórias e são tecidos novos laços de pertencimento ao território, até as comunidades que, com o rock e o rap, rompem e re-imaginam o sentido da convivência, desfazendo e refazendo os rostos e as figuras da identidade. É a partir dessas lições e esperanças que a leitura deste livro contém já a sua inteira reescritura.

Bogotá, outubro de 1998.

${ }^{4}$ Prefácio à edição de 1998, Bogotá, Convenio Andrés Bello.

\section{PREÂMBULO PARA UM MAPA DAS MUTAÇÕES COMUNICATIVAS E CULTURAIS 4}

A cartografia vive de uma ambiguidade que a coloca na confluência da ciência e da arte. Geográfica e histórica, a cartografia produz uma imagem que mostra as relações do ser humano com o território, uma apreensão geral da espessura de seus conflitos e, ao mesmo tempo, mostra a historicidade de nosso conhecimento. Jean-Claude Groshens

O livro que abriga este preâmbulo foi lançado há mais de vinte anos em todo o mundo, em quatro idiomas e publicado por duas editoras, aos quais uma terceira é adicionada agora. Já em sua introdução, escrita em dezembro de 1985, ele demonstrou explicitamente suas tendências cartográficas quando se propôs a investigar a "mestiçagem, que não é apenas a situação racial de que viemos, mas a teia da modernidade e das descontinuidades culturais, das formações sociais e estruturas de sentimento, das memórias e imaginários que misturam o indígena com o rural, o folclore e o popular com o massivo [...]. A aposta e objetivo deste livro é mudar o lugar das questões para tornar os processos de comunicação investigáveis 
a partir das mediações e dos sujeitos, isto é, da articulação entre práticas de comunicação e movimentos sociais". A abundância de signos e sinais que destaca os lugares de onde pensamos e escrevemos, a encruzilhada do conhecimento que transborda suas fronteiras costumeiras, o entrelaçamento de linguagens e figuras com as quais se des-dobra, des-centraliza ou desfaz o campo do conhecimento, são bons exemplos de uma aposta quase iniciática para mapear territórios que julgamos familiares e que, à medida que os percorremos, descobrimos como são estranhos, des-conhecidos e silenciosos, toda a ignorância que ainda habita o conhecimento, resistindo internamente, desconcertando-o e subvertendo-o.

Foi esse sentimento misto de proximidade e estranhamento que me fez reconhecer minha maneira de investigar na figura do "mapa noturno" proposta por Saint-Exupéry para nomear seu mapa de voo e cuja peculiaridade nos é contada colocando-o na boca de um personagem baseado em Guillaumet, um amigo já morto do autor, de quem ele recebeu seu aprendizado para voar sobre a Espanha em voos postais entre a França e a Argélia:

Ele não a estava me descrevendo, mas tornava Espanha minha amiga. Ele não falou comigo sobre a hidrografia ou sobre a população ou sobre Guadix, mas sobre três laranjais que fazem fronteira com um campo perto de Guadix... "Não confie neles, marque-os no seu mapa", repetiu ele. E os três laranjais eram mais importantes no mapa do que a Sierra Nevada. Ele não estava falando de Lorca, mas de uma fazenda perto de Lorca, uma fazenda viva, do fazendeiro e da fazendeira. Esse casal, perdido no espaço a mil e quinhentos quilômetros de nós, adquiriu enorme importância. Bem instalados no pé de sua montanha, como se fossem guardiões de um farol, estavam prontos, sob as estrelas, para ajudar os seres humanos. E aprendemos do seu esquecimento e de sua distância lições sobre detalhes ignorados por todos os geógrafos do mundo.

A navegabilidade de um território viria então, tanto ou mais do que o conhecimento especializado do terreno, de uma certa experiência do piloto sobre o que é verdadeiramente significativo para uma visão de longe, e que, portanto, só se transforma em conhecimento de-cifrando essa visão com abordagens vindas dos outros sentidos: cheiros e sons, memórias e medos, vislumbres e intuições. Assim, a ideia de mediação, que dá título e significado a este livro, foi também o produto de uma experiência que ficou conhecida como sendo instigada por esta outra visão de longe, que é a da filosofia, muitas e densas abordagens ao território da vida social e das culturas cotidianas, abordagens ao mesmo tempo mobilizadoras de sentimentos e sentidos muito diferentes, e mobilizados principalmente a partir da história, da etnografia e desse outro conhecimento ancestral indispensável para desenhar mapas, que é a caligrafia, seu desenhar escrevendo e escrever desenhando. 
Eu escrevi este livro à mão com base em uma infinidade de mapas de cada uma de suas três partes, construídas com lápis de cores diferentes que marcavam a relação de algumas ideias com lugares e eventos, nomes fortes com frases cruzadas com desenhos de trânsitos entre autores e temas. Só mais tarde, quando o digitei, reescrevi para que as costuras e os remendos fossem deixados apenas em seu verso.

Mediações, então, referem-se mais ao traçado que conecta em rede os pontos e linhas dispersos, diferentes e distantes que tecem um mapa para uma realidade que é verificada ou para um conceito que é mantido e gerenciado. Daí minha tenaz resistência em definir mediações, e minha aposta para ir desdobrando-as e delimitando-as à medida que os processos de comunicação, as práticas culturais e os movimentos sociais estavam se tornando próximos, impondo uma relação densa entre o mundo da produção de mídia nas indústrias culturais e os mundos do consumo, massivo, mas diferenciado, ativo e cidadão. Por tudo isso, este preâmbulo tem a tarefa de localizar este livro no longo tempo que vai do desenho de um primeiro mapa que recolhe as linhas de tensão e vislumbre que compõem o campo da comunicação/cultura no final dos anos de 1970, para o traçado do mapa em que trabalho hoje, trinta anos depois. Assim, localizado no final da década de 1980, Dos meios às mediações foi para mim, ao mesmo tempo, o ponto de chegada de quinze anos de trabalho e o ponto de partida de muitos outros.

${ }^{5}$ Traduzido em Martín-Barbero (1983). Todos os parágrafos em itálico pertencem a esse texto ou a este: Martín-Barbero (1980).

\section{O primeiro mapa}

Meu primeiro mapa data do ano de 1980 e está em um texto (Martín-Barbero, $1981^{5}$ ) escrito explicitamente para ser apresentado perante o Comitê Diretivo da Associação Latino-Americana de Pesquisadores de Comunicação (ALAIC), na reunião em que deixei sua presidência e fiz um balanço da pesquisa latino-americana em comunicação durante a segunda metade dos anos setenta. É um mapa em dois níveis que, no entanto, se sobrepõem: um cobre o novo tecido epistêmico e político que se descortinava no final dos anos 1970 para esse campo de conhecimento, e outro traça as linhas emergentes de uma investigação que começou a inserir os estudos de comunicação no campo dos estudos da cultura. O primeiro nível consiste em três pontos: um político, um epistêmico e o cruzamento de ambos. A partir do político, as mudanças importantes começaram a partir de um fato: nos últimos anos o conflito entre o caráter transnacional da estrutura econômica e o caráter nacional da esfera política se tornou insolúvel. Foi só recentemente que a palavra "transnacional" se tornou presente nas ciências sociais, e não deixa de ser premonitório ter sido no campo da comunicação onde talvez tenha se manifestado mais claramente a contradição entre os processos que nomearam a existência do transnacional na economia e do nacional como esfera própria (única) da política. 
Uma contradição que parecia associada, por um lado, à recomposição ideológica de uma direita política que começou a perder a ojeriza a certas questões e está roubando da esquerda alguns dos seus "objetos" mais preciosos, submetendo-os a uma operação de limpeza e neutralização, devido a isso, os campos de batalha já não estão delimitados como há alguns anos. O sentido da luta não é mais claro, isto é, a serviço de quem ou do que estamos trabalhando?

Por outro lado, tomando consciência do que foi dito acima, a era das "grandes denúncias" - sempre necessárias - parece dar lugar a um trabalho mais obscuro, mas não menos arriscado e difícil: a luta contra um amálgama eclético que funcionaliza a crítica, a luta contra o neopositivismo ambiental. Parêntese: é surpreendente constatar que essa contradição, detectada pelos latino-americanos já no final da década de 70 , está hoje levando a alguns dos mais acalorados debates sobre o significado e o alcance da globalização, como foi explicitado nas sucessivas reuniões do Fórum Social Mundial, entre uma esquerda europeia - predominantemente de orientação francesa - que continua a se apegar à esfera nacional como o único campo da batalha política, e a esquerda africana e latino-americana que busca trazer a política para o campo do global!

Do plano epistêmico, o que se des-cobre é que essa funcionalização e, até certo ponto, esse neopositivismo, estava dentro de um pensamento da esquerda - althuseriana, mais especificamente - que continuou investigando a tecnologia apenas a partir de sua dimensão instrumental, a de "aparelho ideológico da classe dominante e seu Estado", ignorando o que as novas tecnologias começaram a moldar: eles aparecem e são percebidos como a matriz de um novo modelo social, e um novo quadro político-cultural. E só colocadas em relação ao modelo de sociedade em que se inscrevem podem ser entendidas as mudanças que essas tecnologias trazem.

É precisamente nesse "ponto" - o terceiro do meu mapa - onde o político e o epistêmico se cruzam tão fortemente quanto evidenciado por uma citação do primeiro Stuart Hall que conheci: "as comunicações estão penetrando no coração do trabalho e do sistema produtivo", e isto através de uma nova ideia de informação como matéria-prima de qualquer produção e até redefinindo os próprios processos de produção, ao mesmo tempo em que no campo político todo o modelo democrático ocidental está sendo afetado pela direção em que caminha a "sociedade informatizada".

A segunda linha, novas tecnologias, visava investigar o que chamava de não contemporaneidade entre tecnologias e usos sociais, o paradoxo desses países, que, ao mesmo tempo em que, pela primeira vez, se sentiram contemporâneos das invenções tecnológicas - alguém escreveu: "pela primeira vez as máquinas não nos chegam em segunda mão" - no entanto, viviam em condições sociais que impediam o acesso a maioria e, em outros casos, um modo de uso que não 
era automático. Isso estava apontando uma tendência que se tornaria bastante fecunda, a de investigar colocando a tecnologia no singular e as culturas no plural para ativar as marcas identitárias que passam pelos usos, incluindo os usos anacrônicos e até estranhos, já que nestes é mais a visível diversidade dos modos de apropriação e, portanto, de nossas culturas, que foi o que a mera análise ideológica do conteúdo ou dos efeitos nos impediu de pensar.

$\mathrm{Na}$ terceira linha, comunicação alternativa ou popular, estava tentando transformar em um objeto de pesquisa participante as outras formas de comunicação em que a fala dos grupos dominados foi liberada, de modo que o que realmente importa é não era o meio, mas a criatividade popular. Compreendendo por populares a memória de outra economia, tanto política quanto simbólica, memória de outra matriz cultural negada. E, então, mais do que uma alternativa em si - fonte de idealizações e maniqueísmos - o que as práticas de comunicação popular nos mostram é o empobrecimento radical que a comunicação cotidiana e festiva sofre com a mercantilização da vida social.

Outros dois mapas mediaram o primeiro mapa e aquele que apresento hoje. Um deles guiou a pesquisa que embasa este livro, possibilitando o estudo das mediações culturais da comunicação, cujos eixos foram: o diacrônico ou histórico, entre matrizes culturais e formatos industriais; e o sincrônico, entre lógicas de produção massiva e competências de recepção ou consumo cultural. O outro mapa, encontrado no Prefácio à quinta edição, feita pelo CAB em Bogotá em

"O texto antecedente a este (N. do E.). $1998^{*}$, foi o que nos anos 1990 me permitiu começar a estudar as mediações comunicativas da cultura, cujos eixos eram as relações entre socialidade cotidiana (a "ação comunicativa") e institucionalidade midiática (o escopo econômico/ legal dos meios de comunicação); e o das relações entre tecnicidade (espessura sociocultural das novas tecnologias) e ritualidade (ligação simbólica da comunicação contemporânea com amplas memórias, seus ritmos mestiços e ritos).

\section{O mapa de trabalho atual}

Desenhando apenas seus traços mais centrais, o mapa que trabalho hoje liga os anteriores ao estudo de mutações culturais contemporâneas, cujos eixos são tempos/espaços e migrações/fluxos. Esboço aqui os pontos e linhas que o traçam.

\section{Estruturas de tempo e formas de espaço}

A grande obsessão do século XIX tem sido a história, o desenvolvimento, a crise, o ciclo, a acumulação, a sobrecarga do passado, a sobrecarga dos mortos e o resfriamento do mundo. Talvez a época atual seja a do espaço, do simultâneo, a justaposição, a 
do próximo e do distante, a do lado a lado, a do disperso. Estamos em um momento em que o mundo é experimentado menos como uma grande vida que se desenvolve ao longo do tempo e mais como uma rede que une pontos e cruza sua meada. Alguns dos conflitos ideológicos que animam as polêmicas ideológicas de hoje desenvolvem-se entre devotos descendentes do tempo e convictos habitantes do espaço.

Michel Foucault (1999)

\section{Temporalidades}

Moderno é aquela temporalidade em que a dinâmica e o peso da história estavam inteiramente focados no futuro em detrimento do passado. Diante do olhar romântico que, desde o século XVIII, buscou recuperar e preservar o que a modernidade tornou irremediavelmente obsoleto - nas línguas e músicas, nas histórias e nos objetos - o olhar ilustrado legitima a destruição do passado como um fardo, e faz da novidade a única fonte de legitimidade cultural. Mas, no início do século XX, W. Benjamin destacou pioneiramente o buraco negro que sugou essa temporalidade: "A representação de um progresso do gênero humano na história é inseparável da representação da realização desta ao lado de um tempo homogêneo e vazio". E é a experiência desse "tempo homogêneo e vazio" que G. Vattimo (1990) revela agora como característica da sociedade da modernidade tardia: a do progresso transformado em rotina, pois a renovação permanente e incessante das coisas, dos produtos, dos bens, é "fisiologicamente necessária para garantir a sobrevivência pura e simples do sistema. A novidade agora não tem nada de revolucionário ou perturbador". Estamos diante de um progresso vazio cuja realidade é confundida com a aparência da mudança produzida pelas imagens. Assim, seguindo Heidegger quando ele fala da ligação da técnica, com um mundo que é constituído por imagens, Vattimo afirma que "o sentido em que a tecnologia se move não é tanto o domínio da natureza pelas máquinas, mas o desenvolvimento específico da informação e da comunicação do mundo como imagem".

Contemporâneo é, em primeiro lugar, uma temporalidade configurada pela crise da experiência moderna do tempo, que tem no corrente boom da memória uma de suas manifestações mais eloquentes. A. Huyssens (1996, 1999) traçou as áreas de expansão em toda a sociedade atual: o crescimento e a expansão de museus nas últimas duas décadas, a restauração de antigos centros urbanos, a ascensão do romance histórico e as narrativas biográficas, moda retrô na arquitetura e no vestuário, o entusiasmo pelas comemorações, a ascensão dos antiquários, o vídeo como dispositivo de memorialização e até a conversão do passado do mundo - e não apenas o recolhido pelos museus - em um banco de dados. A mera enumeração das referências nos dá pistas sobre a onipresença que apresenta e a complexidade da urdidura que alimenta 
a "febre da memória" que nossa sociedade sofre. Um segundo plano da análise diz respeito às várias formas de amnésia que o mercado e a mídia produzem. Vivemos em uma sociedade cujos objetos duram cada vez menos, porque sua obsolescência acelerada é planejada por um sistema cujo funcionamento depende de sua realização. Diante da antiga lembrança acumulada em objetos e casas, por meio da qual várias gerações conversavam, hoje muitos dos objetos que convivemos diariamente são descartáveis e as casas que habitamos ostentam como valor a mais completa assepsia temporal.

Estamos, portanto, diante de uma contemporaneidade que, com seu culto ao presente, "um presente concebido sob a forma de golpes sucessivos sem relação histórica entre eles, e autista, que acredita poder ser autossuficiente" (Lechner, 1995), confunde os tempos e nos esmaga com a simultaneidade do atual. Contemporaneidade que se alimenta especialmente do enfraquecimento do passado e da bricolage dos tempos que nos familiarizam com qualquer outro tempo sem esforço, arrancando as complexidades e ambiguidades de seu tempo. Mas atenção, A. Huyssen nos adverte, revelando a ação do mercado e os meios que no fundo não atingimos, ainda há algo para trás: a obsolescência acelerada e o enfraquecimento de nossos indicadores de identidade estão nos gerando um desejo irreprimível por passado que não se esgota na evasão. Embora moldado pelo mercado, esse desejo existe e deve ser levado a sério como um sintoma de um profundo descontentamento cultural, que expressa a ansiosa indigência que sofremos por mais tempo e a materialidade de nossos corpos reivindicando menos espaço e mais lugar. Tudo isso representa um desafio radical: não opor de forma maniqueísta a memória e a amnésia, mas pensá-las em conjunto. Se a "febre da história" denunciada por Nietzsche no século XIX trabalhou inventando as tradições nacionais e imperiais, isto é, dando coesão cultural a sociedades dilaceradas pelas convulsões da revolução industrial, nossa "febre da memória" é expressão da necessidade de ancoragem temporária sofrida pelas sociedades, cuja temporalidade é brutalmente abalada pela revolução informacional que dissolve as coordenadas espaço-territoriais de nossas vidas. E em que a transformação profunda da "estrutura de temporalidade" que a modernidade legou a nós se manifesta.

\section{Espaços}

O espaço habitado é o espaço primitivo de corpos e territórios. Espaço do nicho, tão perto foneticamente e topograficamente do ninho que, como nos ensinou Heidegger (1987), o habitar precede a construção, é ter um lugar para se encaixar, de modo que todo o construir para o ser humano é a busca permanente de um habitat perfeito, isto é, onde se sinta bem, à vontade. $\mathrm{O}$ espaço habitado se refere à necessidade vital do nicho-lar, um lugar com calor, sem 
o qual o corpo não sobrevive. Não qualquer corpo, mas o que Merleau-Ponty (1945: 114-180) chamou de "corpo próprio", precisamente o que dá forma à sua própria espacialidade. Isso implica que o espaço habitado é inseparável do tempo, porém não o dos relógios, mas sim o tempo que faz e para os quais os mitos da origem e dos ritos de iniciação dão forma, e o tempo dos ritmos do dia: manhã, tarde, noite; das estações do ano: primavera, verão, outono, inverno; e as etapas da vida: infância, juventude, maturidade, velhice. Mas o espaço habitado também mobiliza o que chamamos território: o espaço marcado por balizas de lama ou pedra - outros animais o marcam com urina - e com os quais o clã demarca o terreno do seu trabalho e da sua sobrevivência como comunidade, feita de proximidade e pertença, laços também estreitamente ligados ao tempo, através de rituais que os celebram periodicamente, isto é, os renovam e adensam.

O espaço produzido pela indispensável conexão de alguns territórios com outros, por uma relação de guerras e interdependências que deu origem a uma nova espacialidade. É tecido dos diferentes modos de comunicação produzidos ou demandados por deslocamentos devido a acidentes da natureza, bem como viagens de exploração e conquista. Espaço das vias, das calçadas, dos caminhos, das estradas e também dos veículos, do cavalo ao ônibus espacial. Invenções que foram mudando as formas de viajar e guerrear: do cavalo para a carruagem e o trirreme, e da carruagem para o carro e o tanque, passando pelo navio e pelo avião. As máquinas jogam nos dois sentidos: a bússola que ampliou e garantiu a navegação, estendeu e aumentou o poder das guerras no mar. Paul Virilio (1993) tem tematizado lucidamente a relação entre máquinas de comunicação e máquinas de guerra. E em nossas cidades, cada dia mais extensas, desarticuladas e violentas, o rádio, a televisão e a rede de computadores produzem um novo tipo de espaço compartilhado, capaz de oferecer maneiras de se contrapor ao isolamento de indivíduos e famílias, permitindo-lhes mínimos laços socioculturais. É o desequilíbrio gerado por um tipo de urbanização irracional do espaço que, de alguma forma, é compensado pela espacialidade comunicacional que tece as redes eletrônicas.

O espaço imaginado que nomeia a "comunidade imaginada" nos termos de B. Anderson (1985), na qual o Estado-nação é constituído quando a sociedade moderna entra para substituir a comunidade orgânica pré-moderna. Diante da comunidade orgânica formada por uma densa rede de laços, nos quais se atavam relações de território, de parentesco, de religião e comércio, a sociedade moderna produz uma abstração poderosa, resultando nas duas únicas relações fundadoras: aquela que liga o cidadão com o Estado nacional e do trabalhador com o patrão da fábrica. $O$ espaço imaginado da nação não é apenas a espacialidade chave da modernidade política, mas também da cultural: o que permite ao Estado legitimar-se historicamente é o patrimônio e daí deriva o outro nome da 
nação: pátria. Que por sua vez são traduzidos nos dois componentes, cada dia mais imaginários do nacional: a fronteira e a identidade. Porque nem a fronteira garante a soberania, nem o que nos mantém juntos é essa identidade. Espaço nacional que está no centro não só do debate, mas também dos processos, tanto aqueles que nos remetem aos nacionalismos fundamentalistas, como os que des-localizam e ressignificam o significado desse espaço na globalidade do mundo.

O espaço praticado é a cidade moderna no sentido em que W. Benjamin (1972) a entendeu ao observar a cidade que é formada não apenas pelas novas construções - como avenidas e galerias -, mas pelo anonimato do caminhante das grandes avenidas e pela nova arte que é o cinema. Assim, é a "subjetividade moderna" que emerge na nova relação das pessoas com a cidade, uma nova sensação de solidão que o indivíduo compartilha no meio da multidão com a do espectador de cinema na sala escura, ambos inaugurando dois dispositivos de percepção: o olhar disperso e a montagem da imagem múltipla. A cidade na perspectiva desenhada por M. de Certeau (1980: 175), ao pensar a cidade a partir das maneiras que ela é apropriada: prazer, sofrimento, medos. Pois a cidade se experimenta praticando- $a$, através dos trajetos e dos usos que os habitantes fazem e traçam, essas "motricidades espaciais" combinam estilos coletivos e usos individuais, todos atravessados por mudanças que rompem e reconfiguram os modos de pertencer ao território e modos de viver a identidade. Uma cidade hoje revigorada pela desvalorização do nacional, produzida pela lógica do global nas dinâmicas do local; desafiada pela pluralidade de histórias que hoje são construídas por etnias, pelas regiões e pelas mulheres, o nacional explode e se descentraliza, tornando a cidade o lugar estratégico onde ainda sobrevivem alguns laços de pertencimento, coexistindo com o deslocamento produzido pelos fluxos do global.

\section{Figuras de sensibilidade e mobilidade: migrantes e internautas}

Em vez de opor de forma maniqueísta a cidade habitada por imigrantes à dos cibernautas, os primeiros simbolizando o doloroso desenraizamento de seu território e os últimos celebrando a leveza e a mobilidade dos fluxos, propomos desenvolver as imbricações entre a des-ordem social da integração dos imigrantes na cidade e o desconforto cultural que os cibernautas produzem. O primeiro a não os opor maniqueisticamente tem sido Z. Bauman (1999), diferenciando as figuras do turista e do vagabundo. O turista vive num mundo desespacializado, sem território, por isso sua mobilidade é quase instantânea, tanto quanto o tempo em que vive, mundo em que ficar parado é morrer, e viver é viajar incessantemente acumulando "novas" experiências, sensações e emoções, o mundo do turista é, em última instância, o do consumidor. O vagabundo habita o grosso mundo do espaço com territórios e fronteiras, vistos e desenraizamentos, um território 
ao qual se pertence, mas no qual não se pode ficar parado porque é expulso sem ter outro que possa chamar de seu, já que viajar para ele é sair sem chegar completamente em lugar nenhum, porque o mundo do vagabundo, de acordo com Bauman, é realmente o do emigrante. Hoje, as migrações nas cidades do Norte são uma das causas mais visíveis do caos urbano, que aumentam a extensão e intensidade do heterogêneo, agravando a des-ordem sociocultural. Essa que G. Simmel (2002) previu quando notou que, comparada com a relação segundo a qual o vizinho é aquele que está próximo e o estrangeiro o que está longe, o emigrante é aquele estranho personagem estrangeiro que está nas proximidades, tornando-se um intruso que habita a nossa casa. A presença do imigrante é ressentida pelos cidadãos locais como uma ameaça que, colocando a segurança dos moradores em risco, deve ser combatida, multiplicando os registros, as checagens, ou seja, instalando a desconfiança como comportamento normal e estendendo a suspeita para os gestos, as vozes, as roupas. O maior problema dos imigrantes sudacas, como se denomina os latino-americanos na Espanha, é que, embora acreditem que falam espanhol, seu sotaque os denuncia, pois sua maneira de falar e gesticular alteram a normalidade.

Assim como os fluxos de migrantes causam desordens sociais e políticas na cidade, os fluxos de informação e imagens, as línguas e os escritos virtuais introduzem o caos na cidade letrada, uma vez que também perturbam autoridades e hierarquias. O mundo audiovisual já desafiou a escola na experiência cotidiana do professor que presenciou a mudança na vida escolar por meio de lógicas, conhecimentos e histórias que estão além de seu controle. A mídia audiovisual se tornou um novo e poderoso campo de socialização (Bell, 1977), trata-se da elaboração e transmissão de valores e padrões de comportamento, padrões de gosto e estilos de vida que desorganizam e desmantelam as velhas e resistentes formas de intermediação e autoridade que até recentemente formavam o status e o poder social da família e da escola.

Mas de uma forma muito mais intensiva, a tecnologia digital radicaliza a experiência de des-ancoragem produzida pela modernidade, porque essa tecnologia desloca o conhecimento, modificando tanto o estatuto cognitivo quanto o institucional das condições de conhecimento, levando a uma forte indefinição das fronteiras entre razão e imaginação, conhecimento e informação, natureza e artifício, arte e ciência, conhecimento especializado e experiência profana. Assim, as transformações nas formas pelas quais o conhecimento circula constituem uma das mais profundas transformações que uma sociedade pode sofrer. As experiências e narrativas do imigrante estão cada vez mais interligadas com as dos internautas. Milhões de refugiados e migrantes dentro e fora da América Latina habitam uma cidade escrita com histórias digitadas num chat ou em hipertextos da web, onde 
indivíduos e comunidades se comunicam com seus parentes que estão do outro lado do mundo e isso através da circulação de histórias e imagens, nas quais eles contam e são contados para continuar contando entre os seus e para ser levados em conta por aqueles que, acima deles, tomam decisões que os afetam.

Bogotá, março de 2009.

\section{REFERÊNCIAS}

ANDERSON, B. Comunidades imaginadas: reflexiones sobre el origen y la difusión del nacionalismo. Cidade do México, DF: FCE, 1985.

BAUMAN, Z. La globalización: consecuencias humanas. Buenos Aires: FCE, 1999. BELL, D. Las contradicciones culturales del capitalismo. Madri: Alianza, 1977. BENJAMIN, W. Iluminaciones. Madri: Taurus, 1972. v. 1.

BRUNNER, J. Cambio social y democracia. Estudios Públicos, Santiago, n. 39, p. 239-247, 1990.

DE CERTEAU, M. Linvention du quotidien: arts de faire. Paris: UGdE, 1980. v. 1. FOUCAULT, M. Espacio Otros. Versión, Cidade do México, DF, n. 9, p. 15-26, 1999.

HALL, S. Da diáspora: identidades e mediações culturais. Belo Horizonte: Editora UFMG, 2003.

HEIDEGGER, M. Construir, habitar, pensar. Córdoba: Alción, 1987.

HUYSSENS, A. Memórias do modernismo. Rio de Janeiro: Editora UFRJ, 1996. . La cultura de la memoria: medios, política, amnesia, Crítica Cultural, Santiago de Chile, n. 18, p. 8-15, 1999.

LANDI, O. Reconstrucciones: las nuevas formas de la cultura política. Buenos Aires: Ponto Sur, 1988.

LECHNER, N. América Latina: la visión de los cientistas sociales, Nueva Sociedad, Caracas, n. 139, p. 123-126, 1995.

. Orden y memoria. In: SANCHES, G.; WILLS, M. E. (Comps.). Museo, memoria nación. Bogotá: PNUD; ICANH, 2000. p. 65-79.

MACBRIDE, S. Un solo mundo, voces multiples: comunicación e información en nuestro tiempo. Cidade do México, DF: FCE, 1980.

MARTÍN-BARBERO, J. Comunicación masiva: discurso y poder. Quito: Época, 1978.

. La investigación en las facultades de comunicación: una experiencia y un proyecto. Taller de Comunicación, Santiago de Cali, n. 1, p. 3-14, 1980. . Retos a la investigación de comunicación en América Latina. Comunicación y Cultura, Cidade do México, DF, n. 9, p. 99-113, 1982.

. De quelques défis pour la recherche sur la communication en Amerique Latine. In: MATTELART, A.; STURDZE, Y. (Dirs.). Technologie, culture 
et communication: rapports complémentaires. Paris: La Documentation Française, 1983. v. 2, p. 189-197.

MERLEAU-PONTY, M. Phénoménologie de la perception. Paris: Gallimard, 1945.

MURDOCK, G.; GOLDING, P. Teorías de la comunicación y teorías de la sociedad. In: CURRAN, J.; GUREVITCH, M.; WOOLLACOT, J. (Comps.). Sociedad y comunicación de masas. Cidade do México, DF: FCE, 1981. p. 25-27.

SIMMEL, G. Sobre la individualidad y las formas sociales. Quilmes: Universidade de Quilmes, 2002.

VATTIMO, G. La sociedad transparente. Barcelona: Paidós,1990.

VERÓN, E. El discurso político. Buenos Aires: Hachette, 1987.

VIRILIO, P. L'art du moteur. Paris: Galilée, 1993.

WILLIAMS, R. Marxismo y literatura. Barcelona: Península, 1980. . La política del modernismo. Buenos Aires: Manantial, 1997. 